\title{
Investigation on Molecular Interactions of Multicharged Electrolytes Potassium Pyrophosphate and Potassium Dichromate in Aqueous D-Sorbitol Media at 298.15K by Densiometric and Acoustic Methods
}

\author{
Malabika Talukdar 1,*(iD), Kshirabdhitanaya Dhal ${ }^{1}$ (D) , Sujit Kumar Dehury ${ }^{2}$ (D) \\ Department of Chemistry, ITER, Siksha O Anusandhan Deemed to be University, Bhubaneswar, Odisha, India \\ P.G. Department of Chemistry, Vikram Deb Autonomous College, Jeypore, Odisha, India \\ * Correspondence: malabika136@gmail.com;
}

Scopus Author ID 36603451700

Received: 29.06.2020; Revised: 15.07.2020; Accepted: 16.07.2020; Published: 18.07.2020

\begin{abstract}
Two multicharged electrolytes, potassium pyrophosphate, and potassium dichromate have been taken for densiometric and acoustic studies at 298.15K. Solvents for these electrolytes are 5, 10, and 15 weight $\%$ of D-sorbitol in water. From the density d and ultrasonic velocity U compressibility values, $\mathrm{K}_{\mathrm{S}}, \mathrm{K}_{\mathrm{s}, \phi}, \mathrm{K}_{\mathrm{T}}$ and $\mathrm{W}$ for the solutions, as well as for the solvents, are derived. Other acoustic variables like molar free volume $V_{f}$, internal pressure $\pi_{i}$, relative association $R_{A}$, solvation number $S_{n}^{0}$, acoustic impedance $\mathrm{Z}$ are also calculated. Interpretations of these parameters in the light of molecular interactions are made. It is found that the compressibility of the solutions and the solvent decrease with a concentration of electrolyte and amount of d-sorbitol as a result of the structure breaking property of alkali metal ions and electrostriction of the solvation shells. The presence of strong ion-solvent interaction in the solution is supported by the values of the derived parameters.
\end{abstract}

Keywords: Acoustic studies; ion-solvent interactions; isentropic compressibility; acoustic impedance; electrostriction; solvation cage; structure-breaking properties.

(C) 2020 by the authors. This article is an open-access article distributed under the terms and conditions of the Creative Commons Attribution (CC BY) license (https://creativecommons.org/licenses/by/4.0/).

\section{Introduction}

Electrolytes are important chemicals that find a wide variety of applications from power generation in battery systems, drug delivery in pharmaceutical industries, extraction and refining of metals in metallurgy to electroplating, electroforming and so on. Inside our body, electrolytes play important roles in the proper functioning of nervous and muscular systems and maintaining the water and $\mathrm{pH}$ level in the physiological environment. Electrolytes, as a result of electrostriction, interfere with the arrangement of the solvent molecules in a solution. The effect of electrolytes on the structure, properties, and functions of biologically important molecules can be understood in terms of kosmotropic (structure making) and chaotropic (structure breaking) properties of electrolytes. In order to understand the molecular interactions of these electrolytes dissolved in various aqueous media, the study of physicochemical properties of these systems are in practice. Measurements of density and sound velocity through the electrolyte solutions of different concentrations in different solvent systems lead to the calculations of compressibility values and many other related variables of the mixtures. These parameters are helpful in explaining the molecular interactions present in the binary and 
ternary mixtures. Acoustic studies of electrolytes dissolved in a variety of solvent systems have been carried out by a number of researchers in recent times [1-11]. Samriti Sharma and her coworkers [12] have interpreted the results of volumetric, acoustic and viscometric analysis of L-Histidine in aqueous ionic liquids at different temperatures in terms of ion-solvent and solvent- solvent interactions. Harsh Kumar et al. [13] have reported the result of a volumetric and acoustic study of amino acids in aqueous solutions. Harsh Kumar and his coworker [14] have also discussed the influence of ionic liquids on the volumetric and acoustic properties of amino acids at different temperatures. Pharmaceutical wastes present in water bodies are hazardous to plants, animals, humans, and the environment [15]. Molecular interactions acting in drug solutions are drawing attention of pharmaceutical scientists, chemists, as well as of environmentalists. Acoustic studies play an important role in analyzing the molecular interactions in drug solutions in different aqueous media. Sulochana Singh and her team have studied the molecular interactions of an NSAID paracetamol in aqueous urea [16] and aqueous nicotinamide and sodium salicylate [16] in terms of volumetric and acoustic measurements. In another paper [18] they have reported their volumetric and acoustic studies on ibuprofen in aqueous urea, nicotinamide and sodium salicylate and analyzed the solute-solute and solutesolvent interactions in the ternary mixtures. Volumetric and acoustic studies of diclofenac potassium in aqueous urea medium have also been carried out by Sulochana Singh and her coworkers [19].

Table 1. Specification of chemicals.

\begin{tabular}{|c|c|c|c|c|}
\hline Chemical name & Molecular structure & Molecular weight $(\mathrm{g} / \mathrm{mol})$ & Provenance & $\%$ purity \\
\hline $\begin{array}{l}\text { Potassium } \\
\text { pyrophosphate }\end{array}$ & 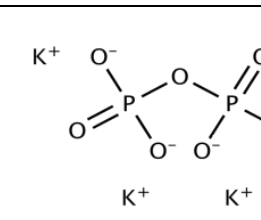 & 330.34 & Merck & $>99 *$ \\
\hline $\begin{array}{l}\text { Potassium } \\
\text { dichromate }\end{array}$ & $\begin{array}{c}\mathrm{Q}_{\mathrm{K}} \\
\mathrm{O} \mathrm{K}^{+} \\
\mathrm{O}^{-}\end{array}$ & 294.18 & Merck & $>99 *$ \\
\hline D-sorbitol & $\mathrm{OH} \quad \mathrm{OH}$ & 182.17 & HIMEDIA & $>99 *$ \\
\hline
\end{tabular}

Sorbitol is a sugar alcohol that is used as a sweetener in food and pharmaceutical industries. As its glycemic index is less than that of other polyols, it has little effect on blood sugar level and is suitable for people with diabetes. Due to its high water solubility, sorbitol can easily penetrate through the cell membrane and is an important entity in the drug delivery system. The present investigation involves acoustic studies on solutions of multicharged electrolytes potassium pyrophosphate and potassium dichromate in water $+\mathrm{D}$-sorbitol mixtures at a constant temperature of $298.15 \mathrm{~K}$. The effect of varying concentrations of the electrolytes as well as of the amount of sorbitol on the acoustic behaviour of the solutions was studied. From the experimental values of sound velocity (U) and density(d) molar isentropic compressibility $\left(\mathrm{K}_{\mathrm{s}}\right)$, limiting molar isentropic compressibility $\mathrm{K}_{\mathrm{s}}^{0}$, apparent molar isentropic compressibility $\left(\mathrm{K}_{\mathrm{s}, \emptyset}\right)$, limiting apparent molar isentropic compressibility $\mathrm{K}_{\mathrm{s}, \emptyset}^{0}$, molar 
isothermal compressibility $\left(\mathrm{K}_{\mathrm{T}}\right)$, molar adiabatic compressibility $(\mathrm{W})$, acoustic impedance $(\mathrm{Z})$, free volume $\left(V_{f}\right)$, internal pressure $\left(\pi_{i}\right)$, relative association $\left(R_{A}\right)$ and solvation number $S_{n}^{0}$ have been calculated. These physico-chemical parameters are proved to be vital in understanding the ion-hydrophilic, ion-hydrophobic, hydrophilic-hydrophilic, and hydrophobic-hydrophobic interactions between the ions, undissociated solute molecules and solvent molecules in the ternary mixtures under study.

\section{Materials and Methods}

\subsection{Materials.}

Specifications of the chemicals used in this experimental work are presented in table 1.

\subsection{Preparation of electrolyte solutions.}

5, 10 and $15 \mathrm{w} \%$ of aqueous D- sorbitol solutions were prepared by dissolving the calculated amount of D- sorbitol in the required amount of deionized water (sp. Cond. $\approx$ $\left.10^{-6} \mathrm{Scm}^{-1}\right)$.

Aqueous D- sorbitol solutions of different compositions were used as the solvents for the electrolyte solutions. Solutions of potassium pyrophosphate and potassium dichromate were prepared by dissolving known weight of electrolyte in a predetermined amount of corresponding solvents, and the concentration is expressed in $\mathrm{mol} / \mathrm{m}^{3}$.

\subsection{Experimental techniques.}

\subsubsection{Density measurement.}

The specific gravity values of solvents and solutions were measured at different temperatures by using a specific gravity bottle, pyknometer $(25 \mathrm{ml})$ with an accuracy of $\pm 0.03 \%$. Weights of the solutions with different concentrations of electrolytes prepared in aqueous D-sorbitol mixtures of varying compositions were measured at 4 different temperatures. Equation (1) was used to calculate the densities of the solutions. Density of the solvent was calculated in a similar method with respect to the literature value of density of pure water.

$$
\mathrm{d}_{2}=\left(\mathrm{W}_{2} / \mathrm{W}_{1}\right) \times \mathrm{d}_{1}
$$

$d_{1}$ and $d_{2}$ are the densities of solvent and solution respectively.

$\mathrm{W}_{1}$ and $\mathrm{W}_{2}$ are weights of solvent and solution respectively.

\subsubsection{Ultrasonic velocity measurement.}

An ultrasonic interferometer (Model F-81, Mittal Enterprise, New Delhi) was used for acoustic studies. The wavelength ( $\lambda$ ) of ultrasonic sound of frequency (f) $2 \mathrm{MHz}$ propagating through the liquid medium is measured at $298.15 \mathrm{~K}$. The sound velocity (U) was calculated with an accuracy of $\pm 0.05 \%$ by using the following equation,

$$
\mathrm{U}=\lambda \times \mathrm{f}
$$




\section{Results and Discussion}

As we have discussed earlier in this article, measuring the velocity and behavior of propagation of a sound wave through different pure and mixed liquid systems is an important method to shed light on the behavior of ionic (and/or) nonionic solutes and organic/inorganic solvents and their interactions with each other in a solution. By solving a series of equations (3-12) involving experimentally obtained density and ultrasonic velocity values, a number of physico-chemical parameters can be obtained. In this section, an attempt has been taken to present the values of these parameters in tabular forms and interpret their variations with a concentration of the electrolytes as well as with the weight percent of D-sorbitol in the solutions. Graphical representations of these variations have been used to reinforce the prediction of ion-ion and ion-solvent interactions present in the solutions under investigation.

\subsection{Ultrasonic velocity and density.}

Table 2 is presenting the values of density $\mathrm{d}\left(\mathrm{kg} \cdot \mathrm{m}^{-3}\right)$ and ultrasonic velocity $\mathrm{U}$ (m. $\mathrm{s}^{-1}$ )and their variations with concentration $\mathrm{c}\left(\mathrm{mol} . \mathrm{m}^{-3}\right.$ ) of $\mathrm{K}_{2} \mathrm{Cr}_{2} \mathrm{O}_{7}$ and $\mathrm{K}_{4} \mathrm{P}_{2} \mathrm{O}_{7}$ in water and in 5, 10 and $15 \mathrm{wt} \%$ (water+D-sorbitol) mixtures at 298.15K. As it was expected, both density $\mathrm{d}$ and ultrasonic velocity $\mathrm{U}$ showed a steady rise with the concentration of electrolytes and the amount of D-sorbitol in solution. With increasing concentration of electrolytes and weight percent of D-sorbitol in solutions association between solute and solvent molecules increases, that in turn increases density and ultrasonic velocity of the solutions. Figure 1 shows that ultrasonic velocity values in $\mathrm{K}_{4} \mathrm{P}_{2} \mathrm{O}_{7}$ solutions are higher than in $\mathrm{K}_{2} \mathrm{Cr}_{2} \mathrm{O}_{7}$ solutions in all wt $\%$ of D-sorbitol. As more number of moles of ions is formed per mole of $\mathrm{K}_{4} \mathrm{P}_{2} \mathrm{O}_{7}$ than of $\mathrm{K}_{2} \mathrm{Cr}_{2} \mathrm{O}_{7}$, the possibility of ion association, hence ion pair formation, is higher for potassium pyrophosphate.

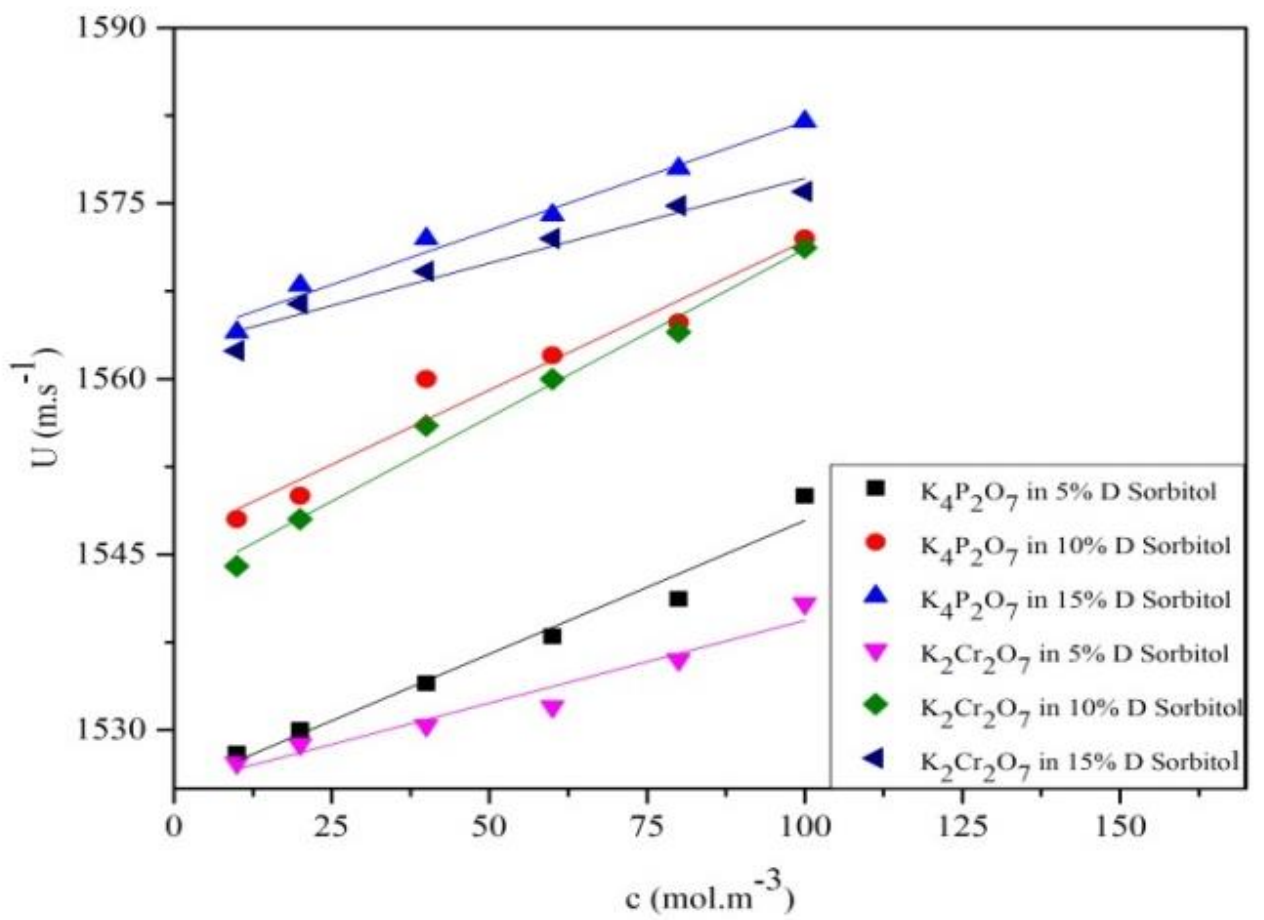

Figure 1. Plot of ultrasonic velocity $U$ with concentration $c$ of $\mathrm{K}_{2} \mathrm{Cr}_{2} \mathrm{O}_{7}$ and $\mathrm{K}_{4} \mathrm{P}_{2} \mathrm{O}_{7}$ in 5 , 10, and $15 \%$ aqueous D- sorbitol at $298.15 \mathrm{~K}$. 
Table 2. The values of concentration $\mathrm{c}\left(\mathrm{mol} \mathrm{m}^{-3}\right)$, density d $\left(\mathrm{Kg} \mathrm{m}^{-3}\right)$, ultrasonic velocity $\mathrm{U}\left(\mathrm{m} \mathrm{s}^{-1}\right)$, molar isentropic compressibility $\mathrm{K}_{\mathrm{s}}\left(\mathrm{m} \mathrm{s}^{2} \mathrm{Kg}^{-1}\right)$, limiting molar isentropic compressibility $\mathrm{K}_{\mathrm{s}}^{0}\left(\mathrm{~m} \mathrm{~s}^{2} \mathrm{Kg}^{-1}\right)$, apparent molar isentropic compressibility $\mathrm{K}_{\mathrm{s}, \phi}\left(\mathrm{m}^{4} \mathrm{Kg} \mathrm{mol} \mathrm{s^{2 }}\right)$ and limiting apparent molar isentropic compressibility $\mathrm{K}_{\mathrm{s}, \phi}^{0}\left(\left(\mathrm{~m}^{4} \mathrm{Kg}\right.\right.$ mol $\left.\mathrm{s}^{2}\right)$ of $\mathrm{K}_{4} \mathrm{P}_{2} \mathrm{O}_{7}$ and $\mathrm{K}_{2} \mathrm{Cr}_{2} \mathrm{O}_{7}$ in 5,10 and $15 \%$ aqueous D Sorbitol

\begin{tabular}{|c|c|c|c|c|c|c|}
\hline $\begin{array}{l}\mathrm{c} \\
\left(\mathrm{mol} \mathrm{m}^{-3}\right)\end{array}$ & $\begin{array}{l}\mathrm{d} \\
\left(\mathrm{Kg} \mathrm{m}^{-3}\right)\end{array}$ & $\begin{array}{l}\mathrm{U} \\
\left(\mathrm{m} \mathrm{s}^{-1}\right)\end{array}$ & $\begin{array}{l}\mathrm{K}_{\mathrm{s}} \times 10^{10} \\
\left(\mathrm{~m} \mathrm{~s}^{2} \mathrm{Kg}^{-1}\right)\end{array}$ & $\begin{array}{l}\mathrm{K}_{\mathrm{s}}^{0} \times 10^{10} \\
\left(\mathrm{~m} \mathrm{~s}^{2} \mathrm{Kg}^{-1}\right)\end{array}$ & $\begin{array}{l}\mathrm{K}_{\mathrm{s}, \phi} \times 10^{10} \\
\left(\mathrm{~m}^{4} \mathrm{Kg} \mathrm{mol} \mathrm{s} \mathrm{s}^{2}\right)\end{array}$ & $\begin{array}{l}\mathrm{K}_{\mathrm{s}, \phi}^{0} \times 10^{10} \\
\left(\mathrm{~m}^{4} \mathrm{Kg} \mathrm{mol} \mathrm{s}^{2}\right)\end{array}$ \\
\hline \multicolumn{7}{|c|}{$\mathrm{K}_{4} \mathrm{P}_{2} \mathrm{O}_{7}$ in $5 \%$ D Sorbitol } \\
\hline 10 & 1017.9 & 1528.0 & 4.208 & \multirow{6}{*}{4.300} & -9.577 & \multirow{6}{*}{-10.755} \\
\hline 20 & 1020.1 & 1530.0 & 4.188 & & -6.255 & \\
\hline 40 & 1023.2 & 1534.0 & 4.153 & & -4.315 & \\
\hline 60 & 1026.7 & 1538.0 & 4.118 & & -3.717 & \\
\hline 80 & 1030.6 & 1541.2 & 4.085 & & -3.401 & \\
\hline 100 & 1034.1 & 1550.0 & 4.025 & & -3.468 & \\
\hline \multicolumn{7}{|c|}{$\mathrm{K}_{4} \mathrm{P}_{2} \mathrm{O}_{7}$ in $10 \%$ D Sorbitol } \\
\hline 10 & 1037.1 & 1548.0 & 4.024 & \multirow{6}{*}{4.111} & -8.909 & \multirow{6}{*}{-10.299} \\
\hline 20 & 1040.0 & 1550.0 & 4.002 & & -6.107 & \\
\hline 40 & 1043.7 & 1560.0 & 3.937 & & -5.049 & \\
\hline 60 & 1046.1 & 1562.0 & 3.918 & & -3.842 & \\
\hline 80 & 1050.3 & 1564.8 & 3.888 & & -3.460 & \\
\hline 100 & 1053.4 & 1572.0 & 3.841 & & -3.359 & \\
\hline \multicolumn{7}{|c|}{$\mathrm{K}_{4} \mathrm{P}_{2} \mathrm{O}_{7}$ in $15 \%$ D Sorbitol } \\
\hline 10 & 1057.6 & 1564.0 & 3.865 & \multirow{6}{*}{3.929} & -6.679 & \multirow{6}{*}{-7.958} \\
\hline 20 & 1060.0 & 1568.0 & 3.837 & & -5.205 & \\
\hline 40 & 1063.1 & 1572.0 & 3.806 & & -3.656 & \\
\hline 60 & 1065.7 & 1574.0 & 3.787 & & -2.913 & \\
\hline 80 & 1070.1 & 1578.0 & 3.753 & & -2.823 & \\
\hline 100 & 1072.8 & 1582.0 & 3.724 & & -2.642 & \\
\hline \multicolumn{7}{|c|}{$\mathrm{K}_{2} \mathrm{Cr}_{2} \mathrm{O}_{7}$ in $5 \%$ D Sorbitol } \\
\hline 10 & 1017.6 & 1527.2 & 4.213 & \multirow{6}{*}{4.274} & -8.507 & \multirow{6}{*}{-9.857} \\
\hline 20 & 1019.1 & 1528.8 & 4.198 & & -5.847 & \\
\hline 40 & 1020.8 & 1530.4 & 4.183 & & -4.246 & \\
\hline 60 & 1023.1 & 1532.0 & 4.164 & & -3.403 & \\
\hline 80 & 1026.0 & 1536.0 & 4.131 & & -3.036 & \\
\hline 100 & 1028.9 & 1540.8 & 4.094 & & -3.025 & \\
\hline \multicolumn{7}{|c|}{$\mathrm{K}_{2} \mathrm{Cr}_{2} \mathrm{O}_{7}$ in $10 \%$ D Sorbitol } \\
\hline 10 & 1037.0 & 1544.0 & 4.045 & \multirow{6}{*}{4.128} & -6.289 & \multirow{6}{*}{-7.075} \\
\hline 20 & 1038.4 & 1548.0 & 4.019 & & -4.209 & \\
\hline 40 & 1039.9 & 1556.0 & 3.972 & & -4.246 & \\
\hline 60 & 1041.7 & 1560.0 & 3.945 & & -2.247 & \\
\hline 80 & 1044.1 & 1564.0 & 3.915 & & -2.254 & \\
\hline 100 & 1047.2 & 1571.2 & 3.868 & & -2.298 & \\
\hline \multicolumn{7}{|c|}{$\mathrm{K}_{2} \mathrm{Cr}_{2} \mathrm{O}_{7}$ in $15 \%$ D Sorbitol } \\
\hline 10 & 1057.3 & 1562.4 & 3.874 & \multirow{6}{*}{3.922} & -4.967 & \multirow{6}{*}{-5.942} \\
\hline 20 & 1058.6 & 1566.4 & 3.850 & & -3.949 & \\
\hline 40 & 1060.9 & 1569.2 & 3.828 & & -2.738 & \\
\hline 60 & 1063.0 & 1572.0 & 3.807 & & -2.308 & \\
\hline 80 & 1066.2 & 1574.8 & 3.782 & & -2.190 & \\
\hline 100 & 1068.4 & 1576.0 & 3.768 & & -1.969 & \\
\hline
\end{tabular}

\subsection{Compressibility parameters.}

3.2.1 Molar isentropic compressibility.

Compressibility is the relative change in the volume of a liquid as a function of pressure acting on it. Molar isentropic and limiting molar isentropic compressibility $\mathrm{K}_{\mathrm{s}}$ and $\mathrm{K}_{\mathrm{s}}^{0}$ are the compressibility coefficients of solution and solvent, respectively. $\mathrm{K}_{\mathrm{s}}$ can be calculated by substituting the experimentally obtained values of ultrasonic velocity $U$ and density $d$ in the well-known Newton-Laplace equation [3]

$$
\mathrm{K}_{\mathrm{s}}=1 / \mathrm{U}^{2} \mathrm{~d}
$$


$\mathrm{K}_{\mathrm{s}}$ values of solutions with different concentrations of electrolytes can be fitted into equation (4) to compute $\mathrm{K}_{\mathrm{s}}^{0}$ for 5,10 and $15 \%$ aqueous D-sorbitol.

$$
\mathrm{K}_{\mathrm{s}}=\mathrm{K}_{\mathrm{s}}^{0}+\mathrm{A}^{\prime} \mathrm{c}+\mathrm{B}^{\prime} \mathrm{c}^{3 / 2}+\mathrm{C}^{\prime} \mathrm{c}^{2}
$$

$\mathrm{A}^{\prime}, \mathrm{B}^{\prime}$ and $\mathrm{C}^{\prime}$ are empirical constants, and $\mathrm{c}$ is the concentration of the electrolytes.

As more number of solvent molecules gets engaged in forming the solvation shells around the ions, the solution becomes increasingly incompressible with increasing ionic concentration in the solution. With an increasing amount of D-sorbitol in the mixtures, more water molecules are displaced from the primary solvation shells making the solutions even less compressible. Lowering of isentropic compressibility $\mathrm{K}_{\mathrm{s}}$ for both the electrolytes, as evident from table 2, is an indication of increasing ion-solvent interactions with increasing concentration of electrolytes and the amount of D-sorbitol in the solutions [7]. The decreasing order of isentropic compressibility of the solvent $\mathrm{K}_{\mathrm{s}}^{0}$ with an increasing amount of D-sorbitol in the solutions can be explained in the light of electrostriction. Pramod Patil and his team studied molar isentropic compressibility and apparent molar isentropic compressibility for amides in $\mathrm{H}_{2} \mathrm{O}$ and $\mathrm{CCl}_{4}$ and discussed solute-solvent interactions [8].

\subsubsection{Apparent molar isentropic compressibility.}

The ability of the water molecules in the hydration shells to compress under pressure with respect to the compressibility of water molecules in the bulk solution is known as apparent molar isentropic compressibility of the solution, $\mathrm{K}_{\mathrm{s}, \phi} \cdot \mathrm{K}_{\mathrm{s}, \phi}^{0}$ is the apparent molar isentropic compressibility of the solution at infinite dilution. $\mathrm{K}_{\mathrm{s}, \phi}$ and $\mathrm{K}_{\mathrm{s}, \phi}^{0}$ can be calculated from the following equations,

$$
\begin{aligned}
\mathrm{K}_{\mathrm{s}, \phi} & =1000 \mathrm{~K}_{\mathrm{s}} \mathrm{c}^{-1}-\mathrm{K}_{\mathrm{s}}^{0} \mathrm{~d}_{0}^{-1}\left(1000 \mathrm{c}^{-1} \mathrm{~d}-\mathrm{M}\right) \\
\mathrm{K}_{\mathrm{s}, \phi} & =\mathrm{K}_{\mathrm{s}, \phi}^{0}+\mathrm{A}^{\prime \prime} \mathrm{c}^{1 / 2}+\mathrm{B}^{\prime \prime} \mathrm{c}
\end{aligned}
$$

$\mathrm{A}^{\prime \prime}$ and $\mathrm{B}^{\prime \prime}$ are empirical constants.

It is apparent from Table 2 that the values of $\mathrm{K}_{\mathrm{s}, \phi}$ and $\mathrm{K}_{\mathrm{s}, \phi}^{0}$ are negative. That implies that apparent molar isentropic compressibility of the water molecules engaged in solvation of the ions is less than the compressibility of the free water molecules in the solution over the whole concentration range of electrolytes [20]. The more negative values of $\mathrm{K}_{\mathrm{s}, \phi}^{0}$ at lower wt $\%$ of D-sorbitol suggest stronger interactions between the ions and the water molecules. With an increasing amount of D-sorbitol, some water molecules are squeezed out of the solvation shells to the bulk solution. As water molecules in the solvation shells are more electrostricted, these are less compressible than the water molecules present in the open structure of the bulk [4]. Therefore, with an increasing amount of D-sorbitol apparent molar compressibility of the solvent becomes less and shows lower negative values. This explanation is, hereby, supported by the fact that $\mathrm{K}_{\mathrm{s}, \phi}^{0}$ values for the solutions of $\mathrm{K}_{4} \mathrm{P}_{2} \mathrm{O}_{7}$ in all compositions of aqueous D-sorbitol are more negative than those for the solutions of $\mathrm{K}_{2} \mathrm{Cr}_{2} \mathrm{O}_{7}$. As more numbers of ions are formed per mole of $\mathrm{K}_{4} \mathrm{P}_{2} \mathrm{O}_{7}$ than per mole of $\mathrm{K}_{2} \mathrm{Cr}_{2} \mathrm{O}_{7}$ on dissociation, more water molecules are involved in the hydration shells in $\mathrm{K}_{4} \mathrm{P}_{2} \mathrm{O}_{7}$ solutions. Hence, the compressibility of the bulk water molecules are reduced and with respect to that apparent molar compressibility of the solvent becomes higher for $\mathrm{K}_{4} \mathrm{P}_{2} \mathrm{O}_{7}$ than for $\mathrm{K}_{2} \mathrm{Cr}_{2} \mathrm{O}_{7}$.

Variation of $\mathrm{K}_{\mathrm{s}, \phi}^{0}$ with the composition of aqueous D-sorbitol solution for both the electrolytes is visible in figure 2. 


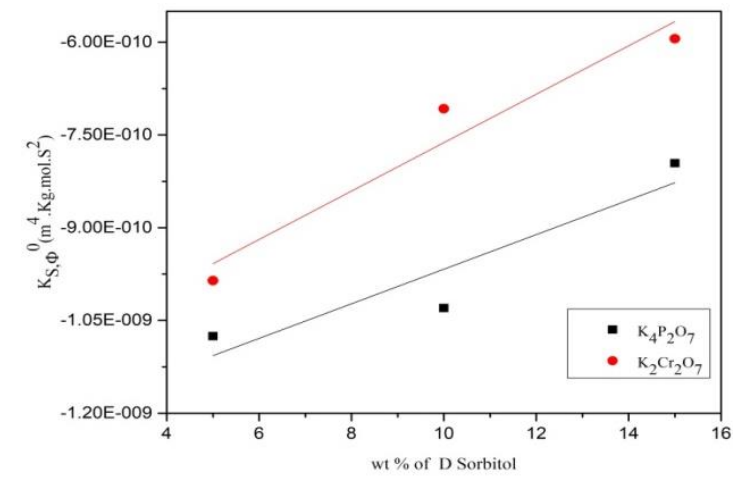

Figure 2. Plot of limiting apparent molar isentropic compressibility $\mathrm{K}_{\mathrm{s}, \phi}^{0}$ with concentration c of $\mathrm{K}_{2} \mathrm{Cr}_{2} \mathrm{O}_{7}$ and $\mathrm{K}_{4} \mathrm{P}_{2} \mathrm{O}_{7}$ indifferent compositions of aqueous D-sorbitol at $298.15 \mathrm{~K}$.

Apparent molar adiabatic compressibility $\mathrm{K}_{\mathrm{T}}$ and apparent molar isothermal compressibility $\mathrm{W}$ are the other two factors used to interpret the ion-solvent interactions in solutions in the light of electrostriction and hydrophobic solvation. The values of $\mathrm{K}_{\mathrm{T}}$ and $\mathrm{W}$ were calculated by equation (7) and (8) respectively and are presented in table 3 .

$$
\begin{aligned}
& \mathrm{K}_{\mathrm{T}}=\frac{17.1 \times 10^{-4}}{\mathrm{~T}^{4} / 9 \mathrm{~d}^{4 / 3} \mathrm{U}^{2}} \\
& \mathrm{~W}=\overline{\mathrm{M}} \mathrm{K}_{\mathrm{S}}^{-1 / 7} \mathrm{~d}^{-1}
\end{aligned}
$$

$\bar{M}$ is the average molecular weight of the solution.

Variations of $\mathrm{K}_{\mathrm{T}}$ and $\mathrm{W}$ with a concentration of potassium dichromate in D-sorbitol solutions at $298.15 \mathrm{~K}$ are displayed in figure 3(a) and (b) and respectively.

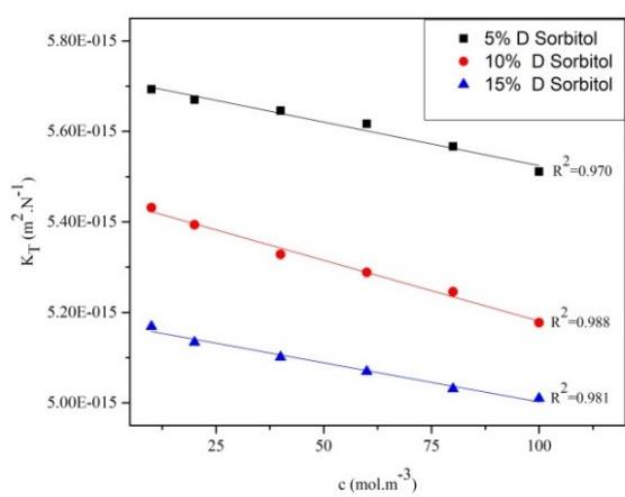

(a)

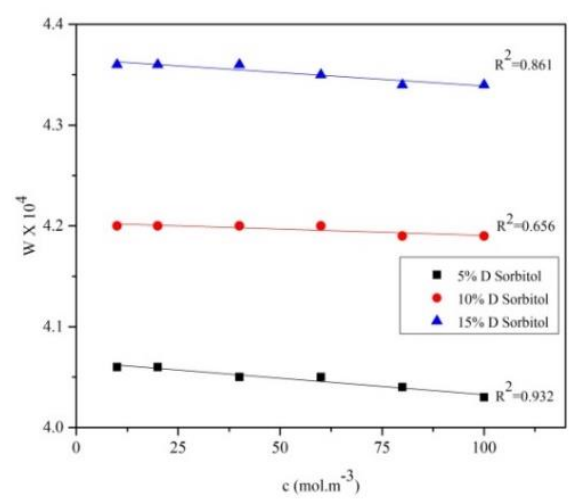

(b)

Figure 3. Variation of (a) adiabatic compressibility $\mathrm{K}_{\mathrm{T}}$ and (b) isothermal compressibility W with concentration $c$ of $\mathrm{K}_{2} \mathrm{Cr}_{2} \mathrm{O}_{7}$ in different compositions of aqueous D-sorbitol at $298.15 \mathrm{~K}$

\subsection{Other acoustic variables.}

3.3.1. Free volume and internal pressure.

Free volume $V_{f}$ is the interstitial space in the solution in which the solute particles are free to move. It can be calculated from the molar volume $V_{m}$ and van der Waals constant $b$ by equation (9).

$$
\mathrm{V}_{\mathrm{f}}=\mathrm{V}_{\mathrm{m}}-\mathrm{b}
$$


Scrutiny of table 3 reveals that free volume $V_{f}$ of the solution bears an ascending linear relationship with the concentration of the electrolytes, as well as with the amount of D-sorbitol in solution. With increasing concentration of ions, the strength of ion-solvent interaction increases, which makes the solvation spheres compact and creates more free space in the bulk of the solution [21]. In a similar fashion, with an increasing amount of D-sorbitol, more water molecules are released from the solvation spheres and the repulsion between the tightly packed solvated ions increases their movement in the solution.

Table 3. Values of concentration $\mathrm{c}\left(\mathrm{mol} \mathrm{m}^{-3}\right)$ adiabatic compressibility $\mathrm{K}_{\mathrm{T}}\left(\mathrm{m}^{2} \mathrm{~N}^{-1}\right)$, relative association $\mathrm{R}_{\mathrm{A}}$ isothermal compressibility $\mathrm{W}$, molar free volume $\mathrm{V}_{\mathrm{f}}\left(\mathrm{m}^{3} \mathrm{~mol}^{-1}\right)$,), internal pressure $\pi_{\mathrm{i}}\left(\mathrm{N} \mathrm{m}^{-2}\right)$, acoustic impedance $\mathrm{Z}\left(\mathrm{Kg} \mathrm{m}^{2} \mathrm{~N}^{-1}\right)$, solvation number $\mathrm{S}_{\mathrm{n}}^{0}$ of $\mathrm{K}_{4} \mathrm{P}_{2} \mathrm{O}_{7}$ and $\mathrm{K}_{2} \mathrm{Cr}_{2} \mathrm{O}_{7}$ in 5, 10, and $15 \%$ aqueous $\mathrm{D}$

Internal pressure $\pi_{i}$ is a measure of binding forces between solute and solvent molecules. $\pi_{\mathrm{i}}$ was computed from equation (10) as follows,

$$
\pi_{\mathrm{i}}=\left(\mathrm{K}_{\mathrm{s}}^{0}-\mathrm{K}_{\mathrm{s}}\right)
$$


The values of varying concentrations of potassium dichromate and potassium pyrophosphate in aqueous D-sorbitol mixtures are exhibited in table 3 . It is found that there is a steady increase in internal pressure $\pi_{i}$ when the concentration of the electrolytes increases in the solution. That implies that strong molecular interaction exists between the ions and the solvent in the solution [22]. However, for the whole range of concentration of the electrolytes, $\pi_{i}$ decreases with an increasing amount of D-sorbitol. That may be due to the disruption in the ion- solvent attraction with the interference of D-sorbitol in the mixture.

$V_{f}$ and $\pi_{i}$ values of potassium pyrophosphate solutions with 5, 10 and $15 \%$ d-sorbitol solutions are plotted against the concentration of the electrolyte and are displayed in figure 4(a) and (b), respectively.

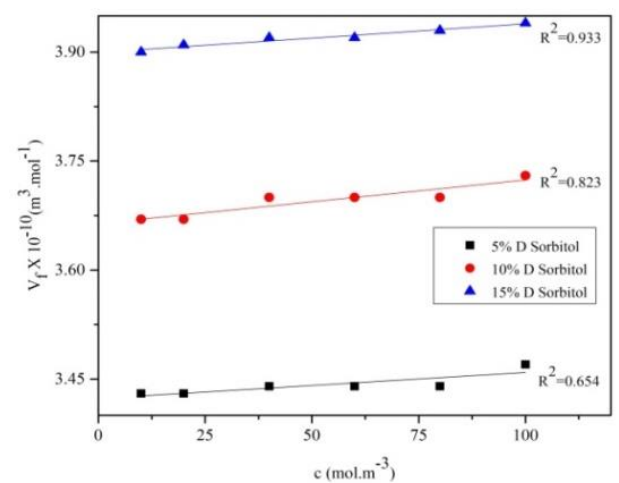

(a)

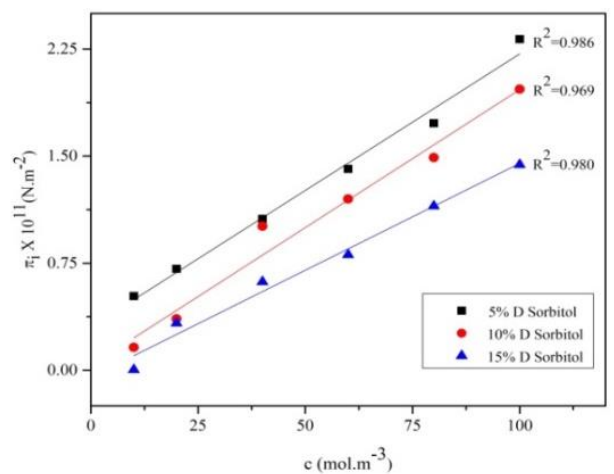

(b)

Figure 4. Plots of (a) free molar volume $V_{f}$ and (b) internal pressure $\pi_{i}$ with concentration c of $\mathrm{K}_{4} \mathrm{P}_{2} \mathrm{O}_{7}$ in aqueous D-sorbitol mixtures at $298.15 \mathrm{~K}$.

3.3.2. Relative association, solvation number and acoustic impedance.

The following equations are used to calculate the values of the relative association $\mathrm{R}_{\mathrm{A}}$, solvation number at infinite dilution $\mathrm{S}_{\mathrm{n}}^{0}$ and acoustic impedance $\mathrm{Z}$,

$$
\begin{gathered}
\mathrm{R}_{\mathrm{A}}=\left(\mathrm{d} / \mathrm{d}_{0}\right) \times\left(\mathrm{U} / \mathrm{U}_{0}\right)^{-1 / 3} \\
\mathrm{~K}_{\mathrm{s}, \phi}^{0}=-\mathrm{S}_{\mathrm{n}}^{0} \mathrm{~V}_{\mathrm{m}}^{0} \mathrm{~K}_{\mathrm{s}}^{0} \\
\mathrm{Z}=\mathrm{Ud}
\end{gathered}
$$

$\mathrm{d}_{0}, \mathrm{U}_{0}$ and $\mathrm{V}_{\mathrm{m}}^{0}$ are the density, ultrasonic velocity, and molar volume of the solvent, respectively.

Relative association $\mathrm{R}_{\mathrm{A}}$ of different components in the medium is a result of structure breaking and structure making properties of solutes. Alkali metal cations play the role of structure breakers in water by weakening the H-bonding network. Due to the breakdown of the tetrahedral structure of water, strong ion-solvent association was found in the solution [23]. A detailed insight into the structure making/breaking ability of a series of amino acids in aqueous isoniazid solutions has been presented by Jyoti Gupta and Anil Kumar Nain [24]. From the increasing trends of $\mathrm{R}_{\mathrm{A}}$ with the concentration of the electrolytes, as arrayed in table 3 , stronger ion-solvent interactions can be elucidated.

The solvation number is the average number of solvent molecules present in the solvation layer around the ions. Due to the caging effect of the solvent, there is a thick and tightly packed solvation shell surrounding the ions. With a higher amount of D-sorbitol, the solvation number is decreasing, as observed in table 3 . When the bulky D-sorbitol molecules are replacing the water molecules from the solvation shells, due to the close proximity of the 
ions and the polar groups (-OH) of D-sorbitol, the ion-hydrophilic interaction increases. The decreasing values of $\mathrm{K}_{\mathrm{s}, \phi}^{0}$ with an increasing amount of D-sorbitol also support the fact.

Acoustic impedance $\mathrm{Z}$ is an important factor in understanding the propagation of a sound wave through a liquid medium. The values of $\mathrm{Z}$ in table 3 suggest that the resistance to the sound waves by the liquid media increases with increasing concentration of ions and the amount of D-sorbitol in the ternary mixtures under investigation. This observation is in accordance with the results reported in the literature [25]. This fact points towards strong ionsolvent and ion-hydrophilic interactions in the solutions.

The relationships between $\mathrm{R}_{\mathrm{A}}$ and $\mathrm{Z}$ with concentration of potassium pyrophosphate are shown in figure 5(a) and (b) respectively.

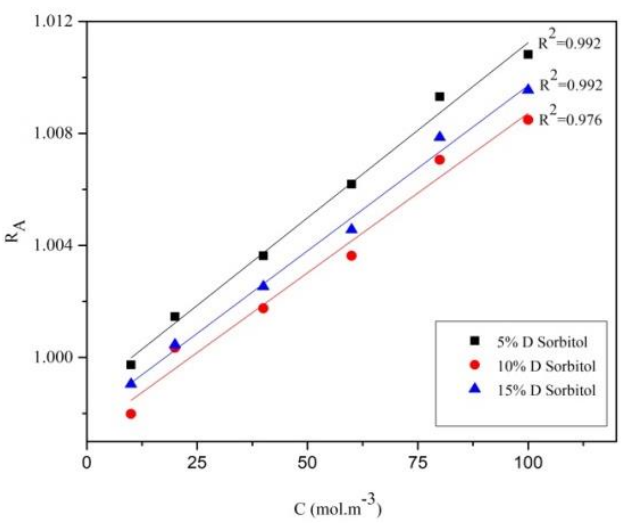

(a)

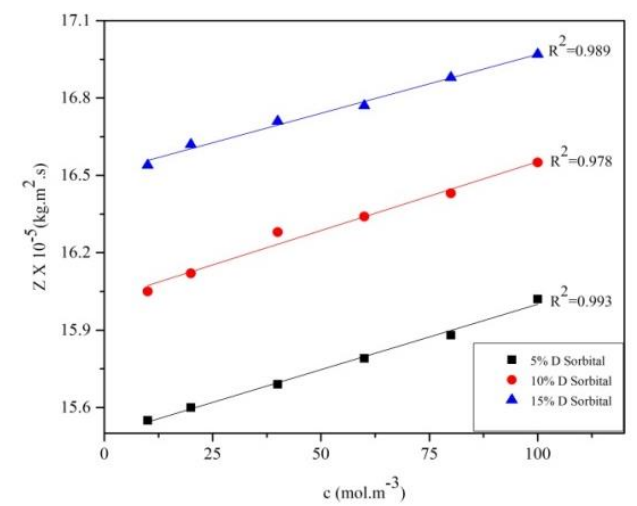

(b)

Figure 5. Plots of (a) relative association $R_{A}$ and (b) acoustic impedance $Z$ with concentration c of $K_{4} P_{2} O_{7}$ in aqueous D-sorbitol mixtures at $298.15 \mathrm{~K}$.

\section{Conclusions}

Electrolytes draw the attention of researchers and scientists in different fields of science due to their varied applications in catalysis, metallurgy, power generation, drug delivery and so on. In order to understand the molecular interactions, densiometric and acoustic studies on the solutions of two multicharged electrolytes, potassium pyrophosphate, and potassium dichromate in aqueous solutions of a sugar alcohol D-sorbitol have been undertaken for this article. The effect of concentration of the electrolytes and the amount of D-sorbitol in the solutions on compressibility factors of the solvent is found to provide important information on interactions between alkali metal ions, D-sorbitol molecules with polar groups (-OH) and non-polar skeleton $\left(-\mathrm{CH}_{2}-\right)$ and water molecules present in the studied solutions. The declining pattern of molar isentropic compressibility $\mathrm{K}_{\mathrm{s}}$ with increasing concentration of electrolytes indicates increasing ion-solvent interaction. As D-sorbitol amount increases in solution due to electrostriction compressibility of the solvent reduces. The variation of molar compressibility at adiabatic and isothermal conditions ( $\mathrm{K}_{\mathrm{T}}$ and $\mathrm{W}$ respectively) with a concentration of electrolytes and weight percent of D-sorbitol supports the fact of increasing electrostriction and stronger ion-solvent interaction. Structure breaking property of metal ions causes disruption to the tetrahedral network in water and favours the formation of solvation shells, compactness of which increases with the amount of D-sorbitol in the solutions. Relative association $R_{A}$, acoustic impedance $Z$, internal pressure $\pi_{i}$ and molar free volume $V_{f}$ all are indicative of strong ion-solvent interactions present in the solutions in the present study. 


\title{
Funding
}

This research received no external funding.

\section{Acknowledgments}

\begin{abstract}
The authors express their heartfelt gratitude to Siksha O Anusandhan Deemed to be University for providing the opportunity to carry out the experimental work necessary for writing this article.
\end{abstract}

\section{Conflicts of Interest}

The authors declare no conflict of interest.

\section{References}

1. Ankita, Nain, A.K. Study on the interactions of drug isoniazid in aqueous-D-xylose/L-arabinose solutions at different temperatures using volumetric,acoustic and viscometric approaches. J. Mol. Liq. 2020, 298, https://doi.org/10.1016/j.molliq.2019.112086.

2. Ibrahima, P.S.S.; Vinayagama, S.C.; Murugan, J.S.; Jeyakumar, J.E. Ultrasonic studies on ternary liquid mixtures of some 1-alkanols with meta methoxy phenol and $\mathrm{n}$ hexane at 313 K. J. Mol. Liq. 2020, 304, https://doi.org/10.1016/j.molliq.2020.112752.

3. Jengathe, S.P.; Dhondge, S.S.; Paliwal, L.J.; Tangde, V.M. Molecular interactions of sodium salicylate in physiological media under the influence of electrolyte/non-electrolyte at different temperatures: Volumetric and acoustic study, J. Chem. Therm. 2017, 115, 221-232, https://doi.org/10.1016/j.jct.2017.08.002.

4. Rani, R.; Kumar, A.; Sharma, T.; Sharma, T.; Bamezai R.K. Volumetric, acoustic and transport properties of ternary solutions of L-serine and L-arginine in aqueous solutions of thiamine hydrochloride at different temperatures. J. Chem. Therm. 2019, 135, 260-277, https://doi.org/10.1016/j.jct.2019.03.039.

5. Kumar, H.; Sharma, M.; Kumar, V. Exploration of solute-solvent interactions in aqueous mixtures of monosaccharides and triammonium citrate (TAC) at different temperatures: Volumetric and acoustic approach. J. Chem. Therm. 2019, 139, https://doi.org/10.1016/j.jct.2019.105877.

6. Dubey, G.P.; Dhingra, L. Acoustic, volumetric, transport and spectral studies of binary liquid mixtures of 2(2-butoxyethoxy) ethanol with amines at different temperatures. J. Chem. Therm. 2020, 149, https://doi.org/10.1016/j.jct.2020.106161.

7. Sharma, S.K.; Nathan, V.; Kumar, D.; Kishore, K. Molecular interaction studies of antibiotic drug Doxycycline Hyclate with aqueous mannitol using volumetric and acoustic methods. J. Mol. Liq. 2017, 231, 647-654, https://doi.org/10.1016/j.molliq.2017.01.001.

8. Patil, P.P.; Shaikh, V.R.; Patil, P.D.; Borse, A.U.; Patil, K.J. Volumetric, isentropic compressibility and viscosity coefficient studies of binary solutions involving amides as a solute in aqueous and $\mathrm{CCl}_{4}$ solvent systems at 298.15 K. J Mol. Liq. 2018, 264, 223-232, https://doi.org/10.1016/j.molliq.2018.05.062.

9. Lomesh, S.K.; Nathan, V.; Bala, M.; Thakur, P. Volumetric and acoustic methods for investigating molecular interactions of antibiotic drug doxycycline hyclate in water and in aqueous solution of sodium chloride and potassium chloride at different temperatures (293.15-313.15) K. J. Mol. Liq. 2019, 284, 241-251, https://doi.org/10.1016/j.molliq.2019.04.006.

10. Sharma, S.K.; Thakur, A.; Kumar, D.; Nathan, V. Thermophysical properties of glycine and glycylglycine in aqueous tartaric acid at different temperatures: Volumetric, acoustic and viscometric studies. J. Mol. Liq. 2020, 297, https://doi.org/10.1016/j.molliq.2019.111941.

11. Ankita, Nain, A.K. Solute-solute and solute-solvent interactions of drug sodium salicylate in aqueousglucose/sucrose solutions at temperatures from 293.15 to $318.15 \mathrm{~K}$ : A physicochemical study. J. Mol. Liq. 2020, 298, https://doi.org/10.1016/j.molliq.2019.112006.

12. Sharma, S.; Singh, M.; Sharma, S.; Singh, J.; Sharma, A.K.; Sharma, M. Molecular interactions of LHistidine in aqueous ionic liquid [C4mim][BF4] solution at different temperatures: Volumetric, acoustic and viscometric approach. J. Mol. Liq. 2020, 303, https://doi.org/10.1016/j.molliq.2020.112596.

13. Kumar, H.; Singh, G.; Kataria, R.; Sharma, S.K. Volumetric, acoustic and infrared spectroscopic study of amino acids in aqueous solutions of pyrrolidinium based ionic liquid, 1-butyl-1-methyl pyrrolidinium bromide. J. Mol. Liq. 2020, 303, https://doi.org/10.1016/j.molliq.2020.112592.

14. Kumar, H.; Sharma, R. Influence of 1-hexyl- 3-methylimidazolium bromide ionic liquid on the volumetric and acoustic properties of amino acids (L-alanine and L-phenylalanine) at different temperatures, J. Mol. Liq., 2020, 304, https://doi.org/10.1016/j.molliq.2020.112666. 
15. Tahvildari, K.; Bigdeli, T. Treatment of pharmaceutical wastewater containing antibiotic with oxidation processes by metallic catalysts. Biointerface Res. Appl. Chem. 2019, 9, 3853-3859, https://doi.org/10.33263/BRIAC92.853859.

16. Singh, S.; Talukdar, M.; Dash, U.N. Studies on molecular interactions in aqueous and aqueous urea systems of paracetamol (N-(4-hydroxyphenyl) ethanamide). J. Mol. Liq. 2018, 265, 679-686, https://doi.org/10.1016/j.molliq.2018.05.092.

17. Singh, S.; Talukdar, M.; Dash, U.N. Ultrasonic studies on paracetamol in aqueous solutions of sodium salicylate and nicotinamide. J. Mol. Liq. 2018, 249, 815-824, https://doi.org/10.1016/j.molliq.2017.11.099.

18. Singh, S.; Talukdar, M.; Dash, U.N. Solute-solvent and solute-solute interactions of ibuprofen in aqueous and in aqueous solutions of urea, sodium salicylate and nicotinamide by volumetric and interferometric techniques. J. Mol. Liq., 2017, 241, 934-945, https://doi.org/10.1016/j.molliq.2017.06.112.

19. Singh, S.; Dhal, K.; Talukdar, M. A Comparative Study on the Effect of Temperature and Concentration on Density, Sound Velocity and their Derived Properties for Diclofenac Potassium in Aqueous Urea Media. Biointerface Res. Appl. Chem. 2020, 10, 6377-6388, https://doi.org/10.33263/BRIAC105.63776388.

20. Khanlarzadeh, K.; Iloukhani, H. Thermo-acoustical and volumetric studies on interionic interactions of Lhistidine in aqueous maltose solutions at different temperatures. J. Mol. Liq. 2018, 271, 421-428, https://doi.org/10.1016/j.molliq.2018.08.158.

21. Parveen, S.; Singh, S.; Shukla, D.; Singh, K.P.; Gupta, M.; Shukla, J.P. Molecular Interaction Study of Binary Mixtures of THF with Methanol and o-Cresol — an Optical and Ultrasonic Study. Acta. Phys. Polo. 2009, 116, 1011-1017, http://dx.doi.org/10.12693/APhysPolA.116.1011.

22. Misra, A.; Vibhu, I.; Singh, R.K.; Gupta, M.; Shukla, J.P. Acoustic, viscometric and optical properties of binary mixtures of tetrahydrofuran with 1-propanol and 2-propanol. J Phys. Chem. Liq. 2007, 45, 93-104, https://doi.org/10.1080/00319100500448182.

23. Waluyo, I.; Nordlund, D.; Bergmann, U.; Schlesinger, D.; Pettersson, L.G.M.; Nilsson, A. A different view of structure-making and structure-breaking in alkali halide aqueous solutions through X-ray absorption spectroscopy. J. Chem. Phys. 2014, 140, https://doi.org/10.1063/1.4881600.

24. Gupta, J.; Nain, A.K. Physicochemical study of solute-solute and solute-solvent interactions of homologous series of $\alpha$-amino acids in aqueous-isoniazid solutions at temperatures from 293.15 to 318.15 K. J. Mol. Liq. 2019, 278, 262-278, https://doi.org/10.1016/j.molliq.2019.01.036.

25. Mehra, R.; Vats, S. Solute-solvent interactions of glycine with urea (aq) $+\mathrm{KBr}(\mathrm{aq})$ at 298, 308 and $318 \mathrm{~K}$. Int. J. Pharm. Bio. Sci. 2010, 1, 523-529. 